\title{
Erratum to: Do captive mandrills invent new gestures?
}

\author{
Mark E. Laidre
}

Published online: 29 October 2009

(C) Springer-Verlag 2009

Erratum to: Anim Cogn (2008) 11:179-187

DOI 10.1007/s10071-007-0121-4

The author kindly thanks Jessica Yorzinski for providing the photo used for Fig. 1a.

The online version of the original article can be found under doi:10.1007/s10071-007-0121-4.

M. E. Laidre

Department of Neurobiology and Behavior,

Cornell University, Ithaca, NY, USA

M. E. Laidre

Department of Zoology,

University of Cambridge, Cambridge, UK

Present Address:

M. E. Laidre $(\square)$

Department of Ecology and Evolutionary Biology,

and Program in Neuroscience,

Princeton University, Princeton, NJ 08544-1003, USA

e-mail: MEL23@cornell.edu 